\title{
Risk factors for wound complications of closed calcaneal fractures after surgery: a systematic review and meta-analysis
}

Wei Zhang ${ }^{1 \dagger}$, Erman Chen ${ }^{1+}$, Deting Xue ${ }^{1 \dagger}$, Houfa Yin $^{2}$ and Zhijun Pan ${ }^{1 *}$

\begin{abstract}
Background: To better clinical outcomes, open reduction and internal fixations (ORIFs) have been commonly performed in the case of closed displaced intra-articular calcaneal fractures (CDICFs). Nonetheless, postoperative wound complications remain a significant problem. Therefore, the aim of our study is to summarise relevant evidence investigating the risk factors for postoperative wound complications of CDICFs following ORIFs.
\end{abstract}

Methods: A meta-analysis was conducted on relevant clinical studies to identify the risk factors for wound complications of CDICFs after ORIFs. Electronic databases were searched for all relevant studies up to October 2014. The Newcastle-Ottawa scale was used to evaluate the methodological quality, and study-specific odds ratios (ORs) were pooled using the fixed-effects model or random-effects model. Sensitivity analysis and meta-regression analysis was performed to evaluate the heterogeneity.

Results: Ten observational studies involving 1559 patients with 1651 fractures were included in this meta-analysis. The results showed that diabetes $(O R, 9.76 ; p<0.01)$, no drainage $(O R, 5.86 ; p<0.01)$, fracture severity $(O R, 3.31$; $p<0.01)$ and bone graft $(\mathrm{OR}, 1.74 ; p<0.01)$ were the risk factors for wound complications of CDICFs after ORIFs. A trend of more wound complications in patients with a history of smoking was detected. However, female patients, ORIFs performed within 14 days of injury, smoking, hypertension and drinking did not significantly increase the risk of wound complications ( $p>0.05$ ).

Conclusions: Based on available relevant evidence, bone graft, diabetes, no drainage and fracture severity were all associated with an increased risk of wound complications after ORIF for CDICFs.

Keywords: Calcaneus, Fracture, Complications, ORIF

\section{Background}

Calcaneal fractures are one of the most common fractures of the hind foot [1]. They generally occur in the setting of high-energy trauma, often resulting in displaced intra-articular calcaneal fractures (CDICFs). Moreover, approximately $75 \%$ of patients with calcaneal fractures had CDICFs [2], which might continue to have devastating consequences for many patients. It also played a major socioeconomic impact with regard to time lost from work and recreation [3]. As the old

\footnotetext{
* Correspondence: panzhijunzw@163.com

${ }^{\dagger}$ Equal contributors

'Department of Orthopedics, Second Affiliated Hospital, School of Medicine, Zhejiang University, Hangzhou, People's Republic of China

Full list of author information is available at the end of the article
}

saying goes, "the man who breaks his heel bone is done, so far as his industrial future is concerned" [4].

There has been a matter of conflict on the treatment of CDICFs. Open reduction and internal fixation (ORIF) would restore calcaneal height, the mechanical axis of the hindfoot and subtalar joint [5], which theoretically provides patients with the possibility of painless weight bearing in daily activities. Several clinical trials reported that patients with ORIF had better clinical outcomes, such as less pain, better clinical scores and later osteoarthritis [6-10]. However, the rapid growth of operative quantity coincided with a considerable rate of wound complications ( $2 \%$ to $27 \%)$ [11,12]. These complications would not only make patients suffer, but increase hospitalisations and expenses [13]. Worse, patients then require 
surgical debridement, hardware removal or myocutaneous flap coverage to eradicate infection.

Therefore, it is important to reduce the rate of wound complications when CDICFs were treated with ORIFs. To identify the risk factors for wound complications, several studies have been published [14-23], but some risk factors remains controversial. In order to provide a reference for clinical practice, it is necessary to have a meta-analysis to evaluate and summarize this issue. The aim of our study was to identify the risk factors for postoperative wound complications of CDICFs after ORIFs.

\section{Methods}

This meta-analysis was performed according to the preferred reporting items for systematic reviews and metaanalyses guidelines (the PRISMA statement) (Additional file 1) [24].

\section{Retrieval strategies}

Electronic databases, including PubMed, Embase and Cochrane library, were searched by three independent researchers (WZ, EMC and DTX), which were published up to October 10, 2014. The following keywords or corresponding Medical Subject Headings (MeSH) were used: "fractures of the os calcis", "calcaneal fractures", "fractures of calcaneum", "fractures of calcaneus", "fractures of hindfoot", "complications", "infection", "debridement", "oozing". Full details of search strategy are included in Additional files 2 and 3. Meanwhile, reference lists of the relevant articles were also retrieved for any additional relevant studies. Languages were not restricted in the search.

\section{Inclusion criteria}

We identified studies according to the following inclusion criteria: (1) participants: human adults (minimum of 18 years of age) with CDICFs; (2) intervention: ORIF; (3) comparison: patients with potential risk factors versus patients without potential risk factors resulting in higher or lower rate of wound complications; (4) sufficient data were available for estimating an odds ratio (OR) with confidence interval (CI).

The following criteria were used for exclusion: (1) minimally invasive reduction and fixation; (2) CDICFs with a primary arthrodesis; (3) animal studies and cadaver studies.

\section{Data extraction}

Three authors (WZ, EMC and DTX) extracted relevant data independently, including the first author's name, study region, study design, average age of participants, the number of case group (patients who experienced wound complications) and control group (patients who did not experience wound complications), operative approach, type of closure (one-layered or double-layered), duration of follow-up, potential risk factor for wound complications, and the number of major complications (including deep infection, osteomyelitis, and postoperative debridement involving hardware removal, free myocutaneous flap wound coverage and even amputation, etc.). In addition, we also tried to contact the authors of the eligible studies to ask for relevant original data for this metaanalysis.

\section{Quality assessment}

In terms of the Newcastle-Ottawa Quality Assessment Scale [25], the methodological quality of each included study was assessed by two independent researchers (WZ and EMC). If disagreements were encountered, they were resolved by discussion with the corresponding author (ZJP). A maximum of nine points was assigned to each study: four for selection, two for comparability, and three for assessment of outcomes (for cohort studies) or exposures (for case-control studies).

\section{Statistical analysis}

The statistical analyses were performed with Stata 12.0 software (StataCorp LP, College Station, Texas, USA). The ORs with corresponding 95\% CIs were considered as the effect estimates for all included studies. Studyspecific ORs were pooled using fixed-effects model or random-effects models. The statistical heterogeneity was assessed with the Q-test and $I^{2} . I^{2}>50 \%$ was considered as high statistical heterogeneity [26]. If $p>0.1$ and $I^{2}<50 \%$, the fixed-effects model was used; otherwise, we used the random-effects model. $I^{2}>50 \%$ was considered as high heterogeneity. Then, sensitivity analysis was conducted by omitting one study at one time and examining the influence of each individual study on the overall OR. To identify the origin of the heterogeneity among studies, we conducted metaregression analysis based on methodological quality or clinical diversity (study design, study region, type of closure, operative approach, etc.). Egger's test and Begg's test were performed to assess the publication bias. For all statistical analyses except heterogeneity and publication bias, a value of $p<0.05$ was regarded as statistically significant, and all tests were two-sided.

\section{Results}

\section{Study selection}

The process of study selection is presented in Figure 1. According to our search strategies, 1065 potential relevant articles were identified initially: 393 from PubMed, 649 from Embase and 23 from the Cochrane library. Of these, 278 studies were excluded as duplicates. After viewing the titles and abstracts of the 787 remaining studies, 15 studies were retrieved in full text. Among 


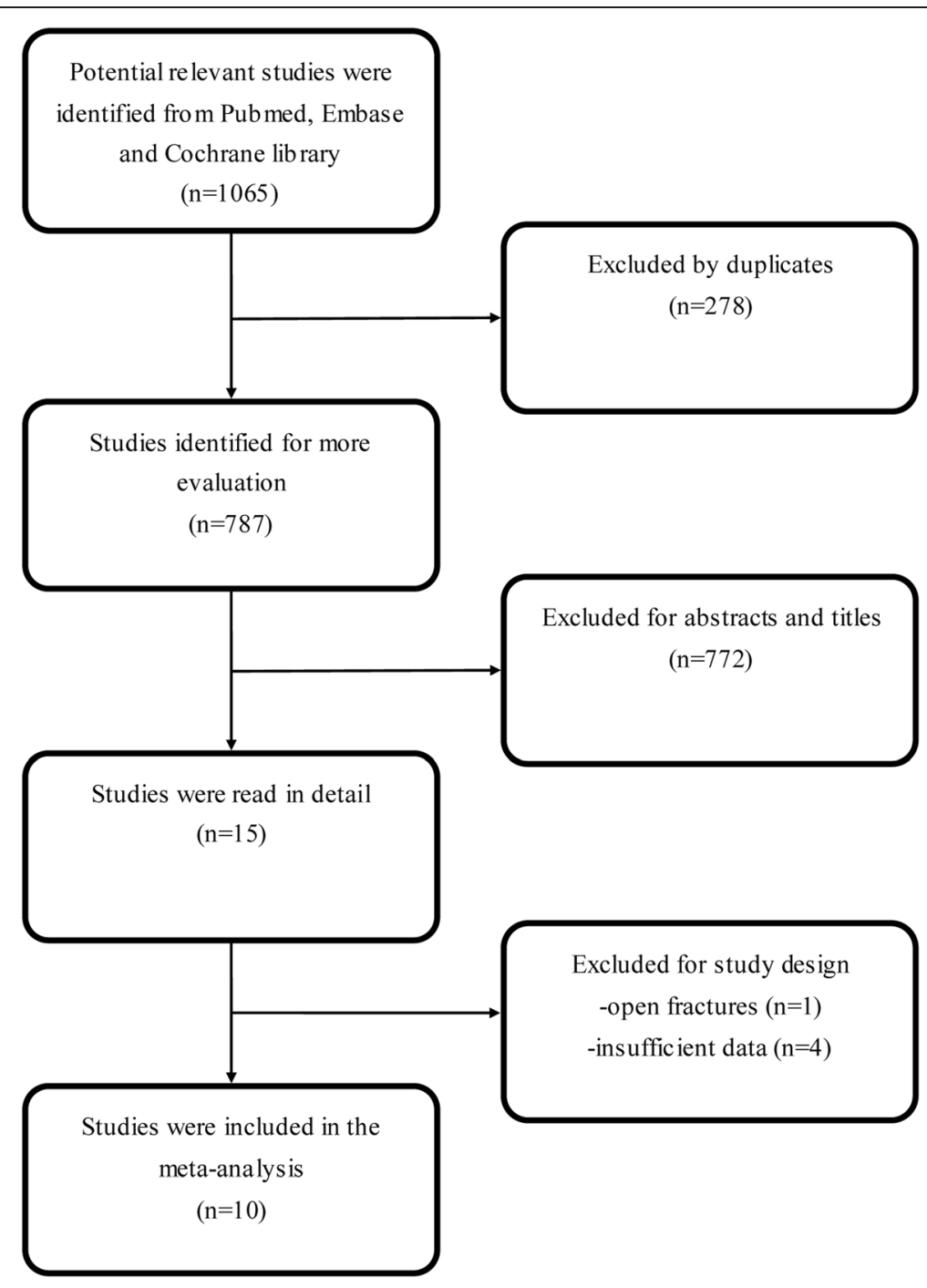

Figure 1 Flow chart summarizing the selection process of studies.

those, one study was excluded due to it involving open calcaneal fractures [27]. Sufficient data were not available in four studies, thus they were also excluded [13,28-30]. Finally, 10 observational studies were included in this meta-analysis [14-23]. There was an excellent interrater agreement between investigators on eligibility $(K=1.0)$.

\section{Study characteristics}

The characteristics of the 10 included studies are presented in Table 1, of which eight studies was case-control studies and two were cohort studies. Among them, three were from Asia, five from Europe, one from America, and one from Oceania, respectively. The dataset involved 1559 patients with 1651 calcaneal fractures, of which 349 fractures were in the case group and 1302 fractures in the control group. The incidence of overall wound complications was $21.1 \%$, including wound edge necrosis, haematoma, wound dehiscence or separation, erythema, infection, etc. The major complications (deep infection, osteomyelitis, surgical treatments including surgical irrigation and debridement, hardware removal, free myocutaneous flap wound coverage and even amputation, etc.) rate was $9.6 \%$, which accounted for $46 \%$ of overall wound complications. The average age was 40.4 years. The standard L-shaped extensile lateral approach was used in six studies, the extended lateral approach was performed in two studies and the surgical approach of the remaining two studies was unavailable. Seven of 10 included studies performed double-layered closure. Follow-up periods ranged from 10.7 months to 48 months.

\section{Study quality}

Table 2 shows the quality of included studies. The average score for the quality assessment of included studies was 7.10. 
Table 1 Study characteristics

\begin{tabular}{|c|c|c|c|c|c|c|c|c|c|c|c|}
\hline \multirow[t]{2}{*}{ Study } & \multirow[t]{2}{*}{ Publication year } & \multirow[t]{2}{*}{ Country } & \multirow[t]{2}{*}{ Study design } & \multicolumn{2}{|c|}{$\begin{array}{l}\text { Group size } \\
\text { (fractures) }\end{array}$} & \multirow[t]{2}{*}{$\begin{array}{l}\text { Total patients } \\
\text { (fractures) }\end{array}$} & \multirow[t]{2}{*}{$\begin{array}{l}\text { Major complications } \\
\text { (fractures) }\end{array}$} & \multirow[t]{2}{*}{$\begin{array}{l}\text { Average } \\
\text { age (years) }\end{array}$} & \multirow[t]{2}{*}{$\begin{array}{l}\text { Operative } \\
\text { approach }\end{array}$} & \multirow[t]{2}{*}{$\begin{array}{l}\text { Closure } \\
\text { method }\end{array}$} & \multirow[t]{2}{*}{$\begin{array}{l}\text { Follow-up period } \\
\text { (months) }\end{array}$} \\
\hline & & & & Case & $\overline{\text { Control }}$ & & & & & & \\
\hline Wu [14] & 2014 & China & Case-control study & 21 & 218 & $209(239)$ & 0 & 37.6 & L-shaped lateral & 2 layer & NA \\
\hline Soni [15] & 2014 & UK & Retrospective cohort study & 10 & 59 & $69(69)$ & 2 & 38.0 & L-shaped lateral & 2 layer & NA \\
\hline Backes [22] & 2014 & Netherlands & Case-control study & 57 & 134 & $191(191)$ & 19 & NA & Extended lateral & 1 layer/2 layer & $>12.0$ \\
\hline Ding [16] & 2013 & China & Case-control study & 87 & 413 & $479(490)$ & 59 & 45.0 & L-shaped lateral & 2 layer & 14.2 \\
\hline Hao [17] & 2013 & China & Case-control study & 17 & 46 & $58(63)$ & 3 & 35.0 & L-shaped lateral & 2 layer & 12.0 \\
\hline Court-Brown [21] & 2009 & UK & Case-control study & 45 & 133 & $178(178)$ & 10 & 41.0 & Extended lateral & NA & NA \\
\hline Koski [18] & 2005 & Finland & Case-control study & 35 & 113 & $126(148)$ & 20 & 39.8 & L-shaped lateral & 2 layer & 10.7 \\
\hline Assous [23] & 2001 & UK & Retrospective cohort study & 13 & 27 & $40(40)$ & 0 & 35.0 & NA & NA & 27.0 \\
\hline Al-Mudhaffar [19] & 2000 & UK & Case-control study & 6 & 27 & $30(33)$ & 2 & 41.0 & NA & 2 layer & 48.0 \\
\hline Folk [20] & 1999 & USA & Case-control study & 58 & 132 & $179(190)$ & 40 & 35.0 & L-shaped lateral & 2 layer & NA \\
\hline Total & - & - & - & 349 & 1302 & 1559 (1651) & 155 & 40.4 & - & - & - \\
\hline
\end{tabular}

$\mathrm{NA}$, not available; major complications included deep infection, osteomyelitis, and operative debridement, etc. 
Table 2 Study quality

\begin{tabular}{|c|c|c|c|c|c|c|c|c|c|}
\hline \multirow{2}{*}{$\begin{array}{l}\text { Case-control } \\
\text { study }\end{array}$} & \multicolumn{4}{|l|}{ Selection } & \multirow{2}{*}{$\begin{array}{l}\text { Comparability } \\
\text { Control for important } \\
\text { factors or additional } \\
\text { factors }\end{array}$} & \multicolumn{3}{|l|}{ Exposure } & \multirow{2}{*}{$\begin{array}{l}\text { Total quality } \\
\text { score }\end{array}$} \\
\hline & $\begin{array}{l}\text { Adequate definition } \\
\text { of cases }\end{array}$ & $\begin{array}{l}\text { Representativeness } \\
\text { of cases }\end{array}$ & $\begin{array}{l}\text { Selection of } \\
\text { controls }\end{array}$ & $\begin{array}{l}\text { Definition of } \\
\text { controls }\end{array}$ & & $\begin{array}{l}\text { Ascertainment } \\
\text { of exposure } \\
\text { (blinding) }\end{array}$ & $\begin{array}{l}\text { Same method of } \\
\text { ascertainment for } \\
\text { subjects }\end{array}$ & $\begin{array}{l}\text { Non-response } \\
\text { rate }\end{array}$ & \\
\hline Wu [14] & 1 & 1 & 1 & 1 & 1 & 1 & 1 & 1 & 8 \\
\hline Backes [22] & 1 & 1 & 1 & 1 & 1 & 1 & 1 & 1 & 7 \\
\hline Ding [16] & 1 & 1 & 1 & 1 & 1 & 1 & 1 & 1 & 8 \\
\hline Hao [17] & 0 & 1 & 1 & 1 & 1 & 1 & 0 & 1 & 6 \\
\hline Court-Brown [21] & 0 & 1 & 0 & 1 & 1 & 1 & 0 & 1 & 5 \\
\hline Koski [18] & 1 & 1 & 1 & 1 & 1 & 1 & 0 & 1 & 7 \\
\hline Al-Mudhaffar [19] & 1 & 1 & 1 & 1 & 1 & 1 & 1 & 1 & 8 \\
\hline Folk [20] & 1 & 1 & 1 & 1 & 1 & 1 & 1 & 1 & 8 \\
\hline \multirow[t]{2}{*}{ Cohort study } & \multicolumn{4}{|l|}{ Selection } & Comparability & \multicolumn{3}{|l|}{ Outcome } & \multirow{2}{*}{$\begin{array}{l}\text { Total quality } \\
\text { score }\end{array}$} \\
\hline & $\begin{array}{l}\text { Representativeness } \\
\text { of the exposed } \\
\text { cohort }\end{array}$ & $\begin{array}{l}\text { Selection of the } \\
\text { non-exposed } \\
\text { cohort }\end{array}$ & $\begin{array}{l}\text { Ascertainment } \\
\text { of exposure }\end{array}$ & $\begin{array}{l}\text { Demonstration that } \\
\text { outcome of interest } \\
\text { was not present at } \\
\text { start of study }\end{array}$ & $\begin{array}{l}\text { Control for important } \\
\text { factors or additional } \\
\text { factors }\end{array}$ & $\begin{array}{l}\text { Assessment } \\
\text { of outcome }\end{array}$ & $\begin{array}{l}\text { Follow-up was } \\
\text { long enough for } \\
\text { outcomes to occur }\end{array}$ & $\begin{array}{l}\text { Adequacy of } \\
\text { follow up of } \\
\text { cohorts }\end{array}$ & \\
\hline Soni [15] & 1 & 1 & 1 & 1 & 1 & 1 & 0 & 1 & 7 \\
\hline Assous [23] & 1 & 1 & 1 & 1 & 1 & 1 & 0 & 1 & 7 \\
\hline
\end{tabular}

Note: A study can be awarded a maximum of 1 point for each numbered item within the Selection and Exposure categories. A maximum of 2 points can be given for Comparability. 


\section{Meta-analysis results}

A meta-analysis of pooled data was performed to analyze the potential risk factors for postoperative wound complications. Table 3 summarizes the pooled results. Bone graft (OR, 1.74; $p=0.007$ ), diabetes (OR, 9.76; $p<0.00001$ ), no drainage (OR, 5.68; $p<0.00001)$ and fracture severity (OR, 3.31; $p<0.00001$ ) were the significant risk factors for postoperative wound complications of CDICFs after ORIFs. However, female patients, ORIFs performed within 14 days of injury, smoking (Figure 2), hypertension, and drinking did not make significant differences in the risk of wound complications $(p>0.05)$. In addition, ORIFs performed within 14 days of injury and smoking did not significantly affect the rate of major wound complications $(p>0.05)$ (Table 4$)$.

High heterogeneity was detected among studies evaluating as potential risk factors for smoking, female patients, and drinking $\left(I^{2}>50 \%\right)$. For smoking, sensitivity analysis was performed. The results demonstrated that the association was similar when one study was omitted at one time (Figure 3). Based on the various diversities (publication year, study design, study quality, region, operative approach, type of closure), we conducted metaregression analysis to find the origin of the heterogeneity among studies, but the results demonstrated that these factors did not significantly influence the association between smoking and the risk of wound complications (Table 5). For female patients, we also performed sensitivity analysis. The result showed that once Backes et al.'s study [22] was excluded, the heterogeneity of the pooled results would drop from $65 \%$ to $3 \%$. However, the pooled outcome was still similar (OR, $1.23 ; p>0.05)$.

According to the results of Begg's test ( $p=0.474$, continuity corrected) and Egger's test ( $p=0.328$, Figure 4$)$, there was no significant publication bias in this study.

\section{Discussion}

The most important finding of the meta-analysis was that bone graft, diabetes, no drainage and fracture severity were identified as risk factors for wound complications of CDICFs after ORIFs, while ORIFs performed within 14 days of injury, smoking, hypertension, drinking and female patients made no significant differences.

\section{Patient-related risk factors}

The results confirmed that fracture severity had a positive correlation on the postoperative wound complications in this study $(\mathrm{OR}=3.31)$, which was consistent with previous results $[21,22,27]$. Backs et al. also reported that an American Society of Anesthesiologists (ASA) classification higher than ASA 1 was associated with an increased risk [22]. The disruption of microcirculation in the soft tissue could be a reason for it [31]. The more severe and complex fractures also increase the operative time that was associated with wound complications.

Our results showed that there was no significant difference in risk of postoperative wound complications between patients with or without a history of smoking, but a trend of more wound complications in patients with smoking history was observed (26.4\% vs. $17.5 \%)$. Consistent results were observed in several studies $[18,21,32,33]$. Based on a recent systematic review that included 6356 patients with fractures, trends toward more superficial and deep infections of postoperative wounds in smokers were noted; however, the differences were also not significant [33]. Nicotine is a vasoconstrictor that reduces nutritional blood flow to the skin, resulting in tissue ischemia and impaired wound healing [16]. Moreover, it could increase platelet adhesiveness thereby raising the risk of thrombotic microvascular occlusion and tissue ischemia [34]. The subcutaneous synthesis of collagen (a critical determinant of the strength of an operative wound) was also impeded by smoking [35]. In addition, Moller et al. found that an effective smoking intervention program six-eight weeks before surgery reduces postoperative morbidity [36]. Based on results, we recommend that a smoking-cessation should be adopted before ORIFs.

Table 3 Pooled results of overall wound complications for potential risk factors

\begin{tabular}{|c|c|c|c|c|c|c|c|}
\hline Potential risk factors & No. of studies & Exposed group & Non-exposed group & Pooled OR & $95 \% \mathrm{Cl}$ & $P$ value & $1^{2}$ \\
\hline Female & 4 & $66 / 299$ & $142 / 618$ & 0.83 & $0.42-1.87$ & 0.59 & $65 \%$ \\
\hline Surgery timing $(\mathrm{d})>14(\mathrm{vs} . \leqq 14)$ & 3 & $32 / 135$ & $48 / 188$ & 0.86 & $0.51-1.46$ & 0.58 & $0 \%$ \\
\hline Bone graft & 4 & $54 / 252$ & $117 / 730$ & 1.74 & $1.17-2.59$ & 0.007 & $49 \%$ \\
\hline Smoking & 10 & $180 / 681$ & $169 / 963$ & 1.90 & $0.97-3.30$ & 0.06 & $80 \%$ \\
\hline Hypertension & 2 & $22 / 114$ & $82 / 384$ & 0.92 & $0.54-1.56$ & 0.75 & $0 \%$ \\
\hline Sanders classification (II.III/IV) & 4 & $37 / 98$ & $134 / 707$ & 3.31 & $2.02-5.44$ & $<0.00001$ & $0 \%$ \\
\hline Diabetes & 4 & 20/33 & $94 / 367$ & 9.97 & $4.43-23.50$ & $<0.00001$ & $0 \%$ \\
\hline Drinking & 2 & $26 / 107$ & $48 / 142$ & 0.85 & $0.19-3.76$ & 0.83 & $55 \%$ \\
\hline No drainage & 2 & $63 / 268$ & $15 / 162$ & 5.68 & $2.91-11.09$ & $<0.00001$ & $0 \%$ \\
\hline Female & 4 & $66 / 299$ & $142 / 618$ & 0.83 & $0.42-1.87$ & 0.59 & $65 \%$ \\
\hline
\end{tabular}




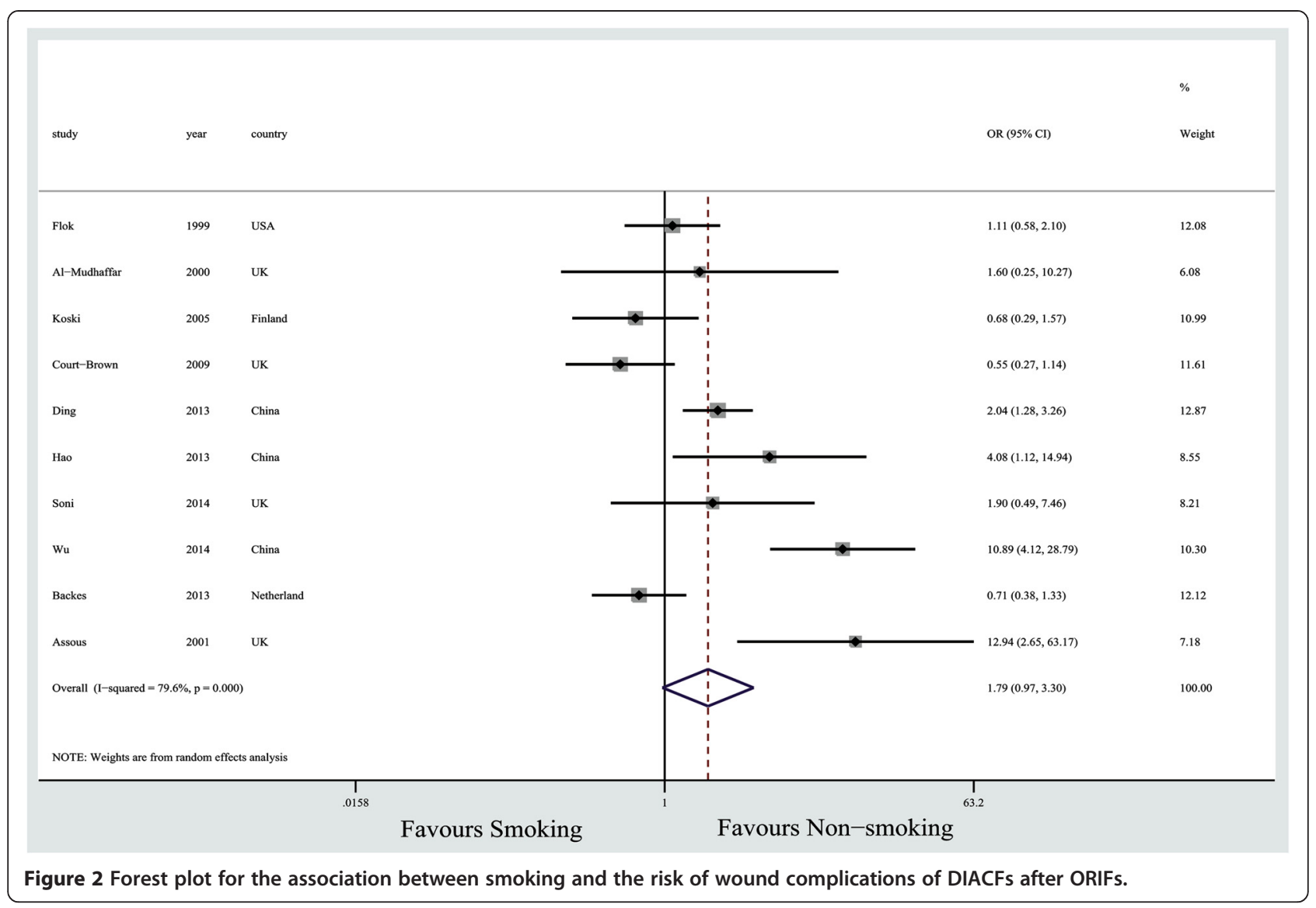

Diabetes was the strongest risk factor for wound complications $(\mathrm{OR}=9.97)$. Patients with diabetes had a 9.97-times greater risk of wound complications when compared with patients without diabetes. It has been demonstrated that diabetes could impede wound healing due to microvascular abnormalities [16].

As for female patients, drinking and hypertension, the results showed that they were not associated with the rate of wound complications. Similar results were reported in previous studies [21,22]. In our study, the average age of patients was relatively young (40.4 years old). The fractures in women generally were caused by relatively lowenergy trauma that produced less severe injuries than those in men [37].

\section{Surgery-related risk factors}

We found that bone grafting would increase the risk of wound complications $(\mathrm{OR}=1.74)$. Similarly, a systematic review revealed that the infection rate in the bone graft group was higher than that in non-graft group $(8.3 \%$ vs. 6.3\%) [38]. Other studies also reported higher complications rate in the treatment of DICAFs with bone grafts $[39,40]$. Bone grafts in this meta-analysis included autogenous and allogenous bone grafts. Due to poor blood supply at the surgical site and serious soft tissue injury, the allogenous bone grafting with weak antibacterial properties might increase wound complications, such as infection and oozing. Meanwhile, for autogenous bone grafts, the procedure of bone-graft harvesting increased the operative time and blood loss. Additionally, the duration of surgery and blood loss was associated with wound complications $[14,16]$. According to a survey, the complication rates associated with harvesting iliac bone grafts can be as high as $40 \%$, including chronic pain, haematoma formation, scarring, nerve injury, and wound problems [41]. Moreover, the medial wall of the CDICF was also fractured, proper filling of the space might be impossible, and the speed of healing did not warrant the

Table 4 Pooled results of major wound complications for potential risk factors

\begin{tabular}{|c|c|c|c|c|c|c|c|}
\hline Potential risk factors & No. of studies & Exposed group & Non-exposed group & Pooled OR & $95 \% \mathrm{Cl}$ & $P$ value & $I^{2}$ \\
\hline Surgery timing $(\mathrm{d})>14(\mathrm{vs} . \leqq 14)$ & 2 & $15 / 125$ & $13 / 135$ & 1.26 & $0.58-2.74$ & 0.57 & $15 \%$ \\
\hline Smoking & 2 & $12 / 117$ & $15 / 134$ & 0.99 & $0.46-2.17$ & 0.99 & $36 \%$ \\
\hline
\end{tabular}






Figure 3 Sensitivity analysis to examine the influence of each individual study on the overall OR of smoking.

extra risk associated with a graft. Several studies found no objective radiographic or functional benefit to the use of bone grafts in the operative treatment of CDICFs $[28,42]$. Given the extra surgical complications and the lack of any demonstrable extra benefit associated with bone grafting, we recommend that it should not be performed during ORIFs for CDICFs.

Our results showed that conditions with no drainage increased the risk of postoperative wound complications $(\mathrm{OR}=5.68)$. A closed suction drain reduces the formation of haematomas thereby decreasing the likelihood of prolonged oozing from the wound, delayed wound healing or infection of the wound [43]. Evidence suggests it is accomplished through increasing blood circulation by angiogenesis, removing oedema, increasing granulation tissue formation, and decreasing bacteria counts $[44,45]$. Based on the data in a multi-centre prospective randomized clinical trial, there was a decreased incidence of wound dehiscence after high-risk fractures when patients have drainage applied to their surgical incision; the risk of infection was 1.9 times higher in control patients treated without drainage [46]. Meanwhile, consistent with several studies detected the similar result [47-49]. Nevertheless, drainage might also become contaminated and act as a conduit for infection, thus timely removals should be a concern.

For surgical timing, there is no difference between whether ORIFs were performed within 14 days of the injuries or later in our study. The correlation between surgical timing and wound complications remains an unsettled issue. Surgeries should be carried out after the condition of soft tissue improves [14]. Nevertheless, if ORIFs were postponed after complete regression of soft tissue oedema, haematoma would occur with the formation of a fibrous bony callus making separation and reduction of fracture fragments difficult, which would influence the final outcomes [50]. Wu et al. found that the risk of wound complications for ORIFs occurring within three days of injury was 5.47 times higher than that of surgeries delayed more than three days. Likewise, Al-Mudhaffar et al. suggest that it could be appropriate to delay ORIFs for at least seven to 10 days or until wrinkling of the skin reappears prior to afflicting a second assault on the soft tissue envelope for all calcaneal fractures requiring surgical interventions [19]. In contrast, Ho et al. reported that if ORIF was performed

Table 5 Meta-regression for variables that influence the association between smoking and risk of wound complications

\begin{tabular}{llll}
\hline Variables & Study variance $\left(\mathbf{t ̦}^{\mathbf{2}}\right)$ & P value & Residual variation due to heterogeneity $\left(\mathbf{I}^{\mathbf{2}}\right)$ \\
\hline Publication year & 1.04 & 0.75 & $80.85 \%$ \\
Study design & 0.86 & 0.26 & $79.73 \%$ \\
Operative approach & 1.06 & 0.89 & $80.70 \%$ \\
Type of closure & 0.94 & 0.35 & $78.99 \%$ \\
Study quality & 0.78 & 0.18 & $74.83 \%$ \\
Study region & 0.88 & 0.26 & $78.71 \%$ \\
\hline
\end{tabular}




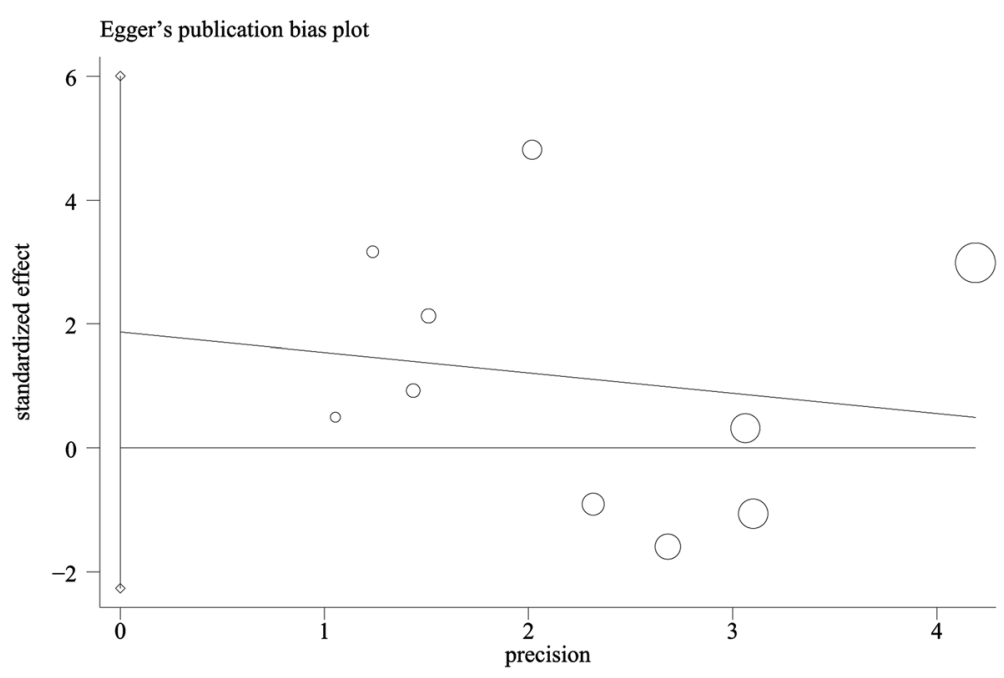

Figure 4 Egger's test to assess the publication bias.

within 48 hours of injury by experienced orthopaedic trauma surgeons, fractures could be stabilized with relatively low rates of wound complications [51]. Meanwhile, Tennent et al. found that the infection rate increased significantly if the interval between injury and operation was greater than 14 days [32]. Therefore, for more objective facts, further high quality randomized controlled trials are required.

In this study, several risk factors were not combined due to inconsistent data forms or insufficient data. Longer operative time [14], prolonged tourniquet time [19], static skin distraction [14], a high number of persons present in the operating room [16], surgeon lacking surgical experience [21], higher body mass index [29] and a single-layer closure method [29] have earlier been identified as the risk factors associated with increased wound complications.

\section{Strengths and limitations}

This study has several strengths. Firstly, to the best of our knowledge, this study is the first meta-analysis that quantitatively summarizes risk factors for wound complications of CDICFs after ORIFs. Secondly, the pooled outcomes are reliable due to our comprehensive data search, rigorous evaluation of methodological quality and the heterogeneity measure. Moreover, most included studies came from level-one trauma centers.

It is undeniable that there are some limitations in this study. First, all the included studies were retrospective cohort studies or case-control studies involving unavoidable recall and interviewer biases. Second, significant heterogeneity was detected in some pooled outcomes. However, after sensitivity analysis, meta-regression analysis and excluded publication bias, the outcomes are reliable. In addition, unadjusted confounding factors, such as the application of antibiotics, the experience of surgeons and the compliance of patients, which could influence the rate of wound complications, were not fully accounted for in several studies.

\section{Conclusions}

Based on available evidences, bone graft, diabetes, no drainage and fracture severity were identified as risk factors for wound complications of CDICFs after ORIFs. Meanwhile, a smoking-cessation should be adopted before ORIFs. Prior to surgical treatment of CDICFs, patients who have the risk factors identified in this study should be counselled concerning the possible complications that might arise after ORIFs. Meanwhile, clinicians should consider the relevant risk factors to choose a better therapeutic strategy. In addition, future well-designed studies should be conducted to confirm these findings.

\section{Additional files}

Additional file 1: Checklist S1 PRISMA checklist for this meta-analysis. Additional file 2: Search strategy for PubMed.

Additional file 3: Search strategy for Embase.

\section{Abbreviations}

Cl: Confidence interval; CDICF: Closed displaced intra-articular calcaneal fracture; ORIF: Open reduction and internal fixation; OR: Odds ratio.

\section{Competing interests}

The authors declare that they have no completing interests.

\section{Author contributions}

ZJP and WZ designed the study. WZ, ERM and DTX acquired and analyzed data. WZ, ERM, DTX and HFY drafted the manuscript. All authors read and approved the final manuscript. 


\section{Funding}

All authors have contributed significantly and are in agreement with the content of the manuscript. All authors have no relevant financial relationships to disclose.

\section{Author details}

${ }^{1}$ Department of Orthopedics, Second Affiliated Hospital, School of Medicine, Zhejiang University, Hangzhou, People's Republic of China. Eye Center, Second Affiliated Hospital of Zhejiang University School of Medicine, Hangzhou, Zhejiang Province, People's Republic of China.

\section{Received: 27 October 2014 Accepted: 7 January 2015} Published online: 08 February 2015

\section{References}

1. Mitchell MJ, Mckinley JC, Robinson CM. The epidemiology of calcaneal fractures. Foot. 2009;19:197-200

2. Cave EF. Fracture of the os calcis-the problem in general. Clin Orthop Relat Res. 1963;30:64-6.

3. Brauer CA, Manns BJ, Ko M, Donaldson C, Buckley R. An economic evaluation of operative compared with nonoperative management of displaced intra-articular calcaneal fractures. J Bone Joint Surg Am. 2005;87:2741-9.

4. Cotton FHF. Results of fracture of the os calcis. J Bone Joint Surg Am. 1916;48:290-8

5. Dhillon MS, Bali K, Prabhakar S. Controversies in calcaneus fracture management: a systematic review of the literature. Musculoskelet Surg. 2011;95:171-81.

6. Agren PH, Wretenberg P, Sayed-Noor AS. Operative versus nonoperative treatment of displaced intra-articular calcaneal fractures: a prospective, randomized, controlled multicenter trial. J Bone Joint Surg Am. 2013;95:1351-7.

7. Nouraei MH, Moosa FM. Operative compared to non-operative treatment of displaced intra-articular calcaneal fractures. J Res Med Sci. 2011;16:1014-9.

8. Howard JL, Buckley R, Mccormack R, Pate G, Leighton R, Petrie DGR. Complications following management of displaced intra-articular calcaneal fractures: a prospective randomized trial comparing open reduction internal fixation with nonoperative management. J Orthop Trauma. 2003;17:241-9.

9. Thordarson DB, Krieger LE. Operative vs. Nonoperative treatment of intraarticular fractures of the calcaneus: a prospective randomized trial. Foot Ankle Int. 1996;17:2-9.

10. O'Farrell DA, O'Byrne JM, Mccabe JP, Stephens MM. Fractures of the os calcis: improved results with internal fixation. Injury. 1993;24:263-5.

11. Benirschke SK, Sangeorzan BJ. Extensive intraarticular fractures of the foot. Surgical management of calcaneal fractures. Clin Orthop Relat Res. 1993;292:128-34

12. Stephenson JR. Surgical treatment of displaced intraarticular fractures of the calcaneus. A combined lateral and medial approach. Clin Orthop Relat Res. 1993;290:68-75.

13. Abidi NA, Dhawan S, Gruen GS, Vogt MT, Conti SF. Wound-Healing risk factors after open reduction and internal fixation of calcaneal fractures. Foot Ankle Int. 1998;19:856-61.

14. Wu K, Wang C, Wang Q, Li H. Regression analysis of controllable factors of surgical incision complications in closed calcaneal fractures. J Res Med Sci. 2014; 19:495-501.

15. Soni A, Vollans S, Malhotra K, Mann C. Association between smoking and wound infection rates following calcaneal fracture fixation. Foot Ankle Spec. 2014;7:266-70

16. Ding $L, H e Z$, Xiao H, Chai L, Xue F. Risk factors for postoperative wound complications of calcaneal fractures following plate fixation. Foot Ankle Int 2013;34:1238-44

17. Hao D, Chen C, Wang D, Yin Y. Non-operation related risk factors of wound complications of calcaneal fractures using lateral extensive L-shaped incision. Zhongguo Xiu Fu Chong Jian Wai Ke Za Zhi. 2013;27:30-5.

18. Koski A, Kuokkanen H, Tukiainen E. Postoperative wound complications after internal fixation of closed calcaneal fractures: A retrospective analysis of 126 consecutive patients with 148 fractures. Scand J Surg. 2005;94:243-5.

19. Al-Mudhaffar M, Prasad CV, Mofidi A. Wound complications following operative fixation of calcaneal fractures. Injury. 2000;31:461-4.
20. Folk JW, Starr AJ, Early JS. Early wound complications of operative treatment of calcaneus fractures: analysis of 190 fractures. J Orthop Trauma. 1999;13:369-72.

21. Court-Brown CM, Schmidt M, Schutte BG. Factors affecting infection after calcaneal fracture fixation. Injury. 2009;40:1313-5

22. Backes M, Schepers T, Beerekamp MSH, Luitse JSK, Goslings JC, Schep NWL. Wound infections following open reduction and internal fixation of calcaneal fractures with an extended lateral approach. Int Orthop. 2014;38:767-73.

23. Assous M, Bhamra MS. Should Os calcis fractures in smokers be fixed? a review of 40 patients. Injury. 2001;32:631-2.

24. Moher D, Liberati A, Tetzlaff J, Altman DG. Preferred reporting items for systematic reviews and meta-analyses: the PRISMA statement. PLoS Med. 2009;6:e1000097.

25. Stang A. Critical evaluation of the Newcastle-Ottawa scale for the assessment of the quality of nonrandomized studies in meta-analyses. Eur J Epidemiol. 2010;25:603-5.

26. Higgins JP, Thompson SG, Deeks JJ, Altman DG. Measuring inconsistency in meta-analyses. BMJ. 2003:327:557-60.

27. Schepers T, Den Hartog D, Vogels LM, Van Lieshout EM. Extended lateral approach for intra-articular calcaneal fractures: an inverse relationship between surgeon experience and wound complications. J Foot Ankle Surg. 2013;52:167-71.

28. Singh AK, Vinay K. Surgical treatment of displaced intra-articular calcaneal fractures: Is bone grafting necessary? J Orthop Traumatol. 2013;14:299-305.

29. Shuler FD, Conti SF, Gruen GS, Abidi NA. Wound-healing risk factors after open reduction and internal fixation of calcaneal fractures: Does correction of Bohler's angle alter outcomes? Orthop Clin N Am. 2001;32:187-92.

30. Benirschke SK, Kramer PA. Wound healing complications in closed and open calcaneal fractures. J Orthop Trauma. 2004;18:1-6.

31. Berry GK, Stevens DG, Kreder HJ, Mckee M, Schemitsch E, Stephen DJ. Open fractures of the calcaneus: a review of treatment and outcome. J Orthop Trauma. 2004;18:202-6.

32. Tennent Td CPSR. The operative management of displaced intra-articular fractures of the calcaneum: a two-centre study using a defined protocol. Injury. 2001:32:491-6.

33. Scolaro JA, Schenker ML, Yannascoli S, Baldwin K, Mehta S, Ahn J. Cigarette smoking increases complications following fracture: A systematic review. J Bone Joint Surg Am. 2014;96:674-81.

34. Padmavathi $P$, Reddy VD, Maturu P, Varadacharyulu N. Smoking-induced alterations in platelet membrane fluidity and $\mathrm{Na}(+) / \mathrm{K}(+)$-ATPase activity in chronic cigarette smokers. J Atheroscler Thromb. 2010;17:619-27.

35. Jorgensen LN, Kallehave F, Christensen E, Siana JE, Gottrup F. Less collagen production in smokers. Surgery. 1998;123:450-5.

36. Moller AM, Villebro N, Pedersen T, Tonnesen H. Effect of preoperative smoking intervention on postoperative complications: a randomised clinical trial. Lancet. 2002;359:114-7.

37. Barla J, Buckley R, Mccormack R, Pate G, Leighton R, Petrie D, et al. Displaced intraarticular calcaneal fractures: long-term outcome in women. Foot Ankle Int. 2004;25:853-6.

38. Yang Y, Zhao H, Zhou J, Yu G. Treatment of displaced intraarticular calcaneal fractures with or without bone grafts: a systematic review of the literature. Indian J Orthop. 2012;46:130-7.

39. Huang PJ, Huang HT, Chen TB, Chen JC, Lin YK, Cheng YM, et al. Open reduction and internal fixation of displaced intra-articular fractures of the calcaneus. J Trauma. 2002;52:946-50.

40. Baumgaertel FR, Gotzen L. Two-stage operative treatment of comminuted os calcis fractures. Primary indirect reduction with medial external fixation and delayed lateral plate fixation. Clin Orthop Relat Res. 1993;290:132-41.

41. Silber JS, Anderson DG, Daffner SD, Brislin BT, Leland JM, Hilibrand AS. Donor site morbidity after anterior iliac crest bone harvest for single-level anterior cervical discectomy and fusion. Spine (Phila Pa 1976). 2003;28:134-9.

42. Longino D, Buckley RE. Bone graft in the operative treatment of displaced intraarticular calcaneal fractures: Is it helpful? J Orthop Trauma. 2001;15:280-6.

43. Parker MJ, Livingstone V, Clifton R, Mckee A. Closed suction surgical wound drainage after orthopaedic surgery. Cochrane Database Syst Rev. 2007;5:D1825.

44. Chen SZ, Li J, Li XY, Xu LS. Effects of vacuum-assisted closure on wound microcirculation: an experimental study. Asian J Surg. 2005;28:211-7. 
45. Gouttefangeas C, Eberle M, Ruck P, Stark M, Muller JE, Becker HD. Functional T lymphocytes infiltrate implanted polyvinyl alcohol foams during surgical wound closure therapy. Clin Exp Immunol. 2001;124:398-405.

46. Stannard JP, Volgas DA, Mcgwin GR, Stewart RL, Obremskey W, Moore T. Incisional negative pressure wound therapy after high-risk lower extremity fractures. J Orthop Trauma. 2012;26:37-42.

47. Masden D, Goldstein J, Endara M, Xu K, Steinberg J, Attinger C. Negative pressure wound therapy for at-risk surgical closures in patients with multiple comorbidities: a prospective randomized controlled study. Ann Surg. 2012;255:1043-7.

48. Stannard JP, Robinson JT, Anderson ER, Mcgwin GJ, Volgas DA, Alonso JE. Negative pressure wound therapy to treat hematomas and surgical incisions following high-energy trauma. J Trauma. 2006;60:1301-6.

49. Ingargiola MJ, Daniali LN, Lee ES. Does the application of incisional negative pressure therapy to high-risk wounds prevent surgical site complications? A systematic review. Eplasty. 2013;13:e49.

50. Epstein N, Chandran S, Chou L. Current concepts review: intra-articular fractures of the calcaneus. Foot Ankle Int. 2012;33:79-86.

51. Ho CJ, Huang HT, Chen CH, Chen JC, Cheng YM, Huang PJ. Open reduction and internal fixation of acute intra-articular displaced calcaneal fractures: A retrospective analysis of surgical timing and infection rates. Injury. 2013:44:1007-10.

\section{Submit your next manuscript to BioMed Central and take full advantage of:}

- Convenient online submission

- Thorough peer review

- No space constraints or color figure charges

- Immediate publication on acceptance

- Inclusion in PubMed, CAS, Scopus and Google Scholar

- Research which is freely available for redistribution 